\title{
EKSTRÜDER VİDALAR İÇİN AŞINMAYA DİRENÇLİ KROM OKSİT ESASLI KAPLAMALARIN ÜRETIMI VE KARAKTERİZASYONU
}

\author{
Ali İlkay SEMERCi', Ekrem ALTUNCU² \\ ${ }^{1}$ Sakarya Uygulamalı Bilimler Üniversitesi, Lisansüstü Eğitim Enstitüsü, Metalurji ve Malzeme Mühendisliği \\ Bölümü Yüksek Lisans Programı, Sakarya, Türkiye \\ ${ }^{2}$ Sakarya Uygulamalı Bilimler Üniversitesi, Teknoloji Fakültesi, Metalurji ve Malzeme Mühendisliği Bölümü, \\ Sakarya, Türkiye
}

\begin{tabular}{|c|c|}
\hline Anahtar Kelimeler & Öz \\
\hline $\begin{array}{l}\text { Ekstrüder Vida, } \\
\text { Așınma, } \\
\text { Yüzey İșlemleri, } \\
\text { Alev Sprey. }\end{array}$ & 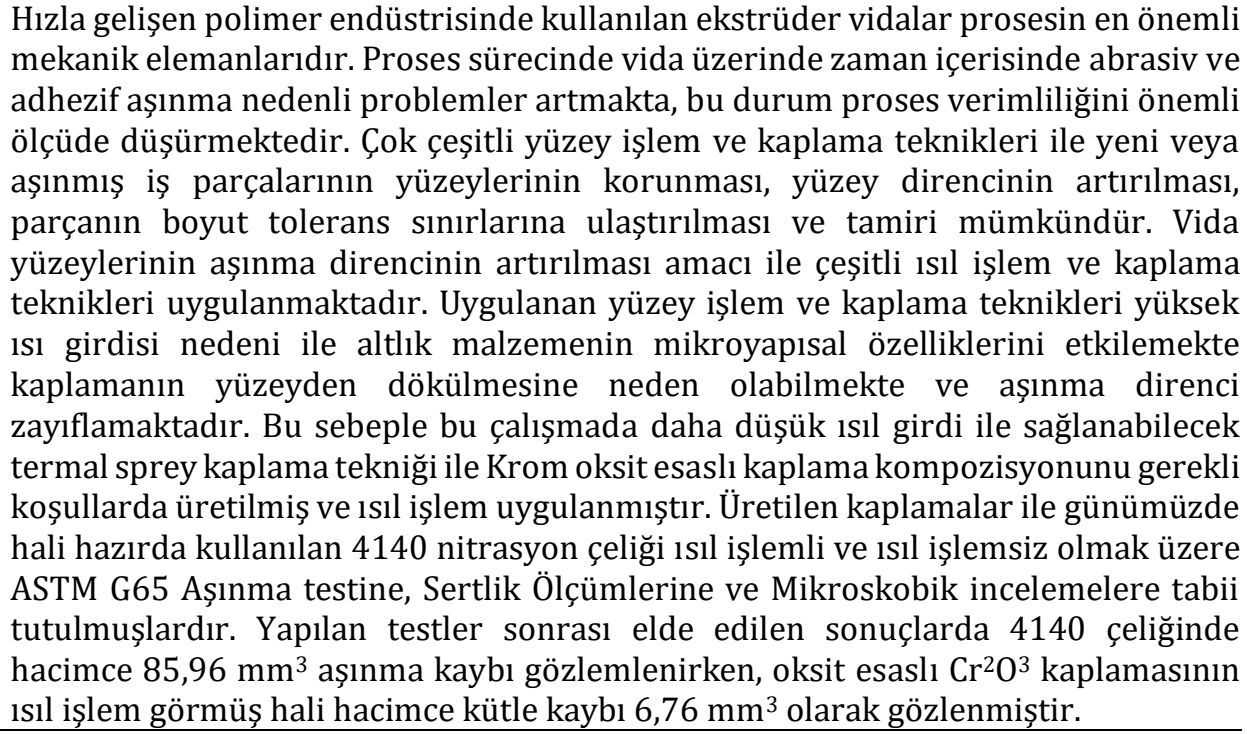 \\
\hline
\end{tabular}

\section{PRODUCTION AND CHARACTERIZATION OF WEAR-RESISTANT CHROME OXIDE BASED COATINGS FOR EXTRUDER SCREWS}

\begin{tabular}{l}
\hline Keywords \\
Extruder Screw, \\
Wear, \\
Surface Treatments, \\
Flame Spray.
\end{tabular}

* ilgili yazar / Corresponding author: ilkay_semerci@hotmail.com, +90-545-818-1536

\begin{abstract}
Extruder screws used in the rapidly developing polymer industry are the most important mechanical elements of the process. During the process, problems caused by abrasive and adhesive wear increase over time on the screw, which significantly reduces process efficiency. With various surface treatment and coating techniques, it is possible to protect the surfaces of new or worn work pieces, increase the surface resistance, reach the size tolerance limits and repair. Various heat treatment and coating techniques are applied to increase the wear resistance of the screw surfaces. The applied surface treatment and coating techniques affect the microstructural properties of the substrate material due to high heat input, causing the coating to be poured from the surface and its wear resistance is weakened. For this reason, in this study, chrome oxide based coating composition was produced under necessary conditions and thermal treatment was applied with the thermal spray coating technique that can be provided with lower thermal input. 4140 nitration steel, which is currently used with the coatings produced, has been subjected to ASTM G65 Abrasion test, Hardness Measurements and Microscopic examinations, with and without heat treatment. $\mathrm{n}$ the results obtained after the tests, a wear loss of $85.96 \mathrm{~mm}^{3}$ in volume was observed in 4140 steel, while the heat treatment of oxidebased $\mathrm{Cr}_{2} \mathrm{O}_{3}$ coating was observed as mass loss in volume of $6.76 \mathrm{~mm}^{3}$.
\end{abstract}




\section{Alıntı / Cite}

Semerci, A.İ., Altuncu, E., (2021). Ekstrüder Vidalar İçin Așınmaya Dirençli Krom Oksit Esaslı Kaplamaların Üretimi Ve Karakterizasyonu, Mühendislik Bilimleri ve Tasarım Dergisi, 9(4), 1236-1245.

\begin{tabular}{l|l|l}
\hline Yazar Kimliği / Author ID (ORCID Number) & \multicolumn{3}{|l}{ Makale Süreci / Article Process } \\
\hline A.İ Semerci, 0000-0002-7476-9379 & Başvuru Tarihi / Submission Date & 07.08 .2020 \\
E. Altuncu, 0000-0002-1395-9013 & Revizyon Tarihi / Revision Date & 16.09 .2021 \\
& Kabul Tarihi / Accepted Date & 13.11 .2021 \\
& Yayım Tarihi / Published Date & 20.12 .2021 \\
\hline
\end{tabular}

\section{Giriş (Introduction)}

Günümüzde hızla gelişen yüzey mühendisliği konuları kapsamında çok çeșitli yüzey işlem, ısıl işlem ve yüzey kaplama tekniklerinin kullanımıyla, metalik esaslı iş parçalarının (ekstrüzyon vidaları gibi) yüzeylerinin korunması, yüzey direncinin ve aşınma direncinin artırılması, hasar görmüş veya aşınmış bir parçanın boyut tolerans sınırlarına ulaştırılması ve tamiri mümkündür. Bu avantaj; parça yenileme maliyetlerinin ve bakım maliyetlerinin azalmasına bunun yanında parça ömrünün ve proses verimliliğinin artışına neden olmaktadır. Hızla gelişen polimer endüstrisinde kullanılan ekstrüder vidalar, prosesin en önemli mekanik elemanlarıdır. Proses sürecinde vida üzerinde zamanla çok çeşitli nedenlerden (tasarımsal hatalar, yanlış malzeme seçimi, yanlış yüzey/ kaplama/ tamir uygulamaları, anormal çalışma şartları ve farklı kompozisyonlarda hammaddeye dayalı üretim vb.) kaynaklı olarak abrasiv, adhezif ve korozif aşınma nedenli problemler artmaktadır. Bu durum proses verimliliğini ve ürün kalitesini önemli ölçüde düşürmektedir. Üretim yapan bir firmada üretim duruşu, bakım, tamir ve yenileme nedenli kayıplar sonucunda ürün kalitesinde ve üretim kapasitesinde azalma oldukça önemli mali kayıplara yol açmaktadır. Bu bağlamda en etkin çözüm uygun kaplama kompozisyonu ile birlikte uygun kaplama yönteminin belirlenmesi ve doğru şekilde uygulanmasıdır.

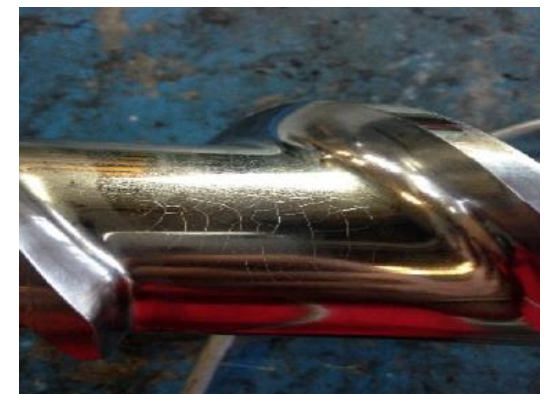

Şekil 1. Ekstrüder vidası aşınma bölgesi (Extruder screw wear zone)

Ekstrüder vida yüzeylerinin aşınma direncinin artırılması amacı ile çeşitli ısıl işlem (nitrasyon) ve kaplama teknikleri (plazma transfer ark (PTA), sert krom, termal sprey) uygulanmaktadır. Mevcut durumunda PTA teknikleri ile kobalt esaslı karbür takviyeli toz (stellite) türleri kullanılarak uygulanan dolgu sert kaplama tekniklerinde prosesin doğası gereği tozu ergitmek ve yüzeyde biriktirmek için harcanan yüksek ısı girdisi nedeni ile altlık malzemenin ve kaplamanın mikro yapısal özelliklerini etkilemekte termal gerilmeler etkisiyle kaplamanın yüzeyden dökülmesine neden olabilmekte ve tane irileşmesi, karbür azalması sonucunda sertlik dalgalanması artmakta ve aşınma direnci zayıflamaktadır. Sert krom kaplamalar ise yeterli sertlik direncini sağlamakta zorlanmaktadır. Bu bağlamda termal sprey kaplama yöntemleri birçok açından avantaj ve esneklik göstermektedir. Gerek kaplama kompozisyonu çeşitliliği gerekse kaplama özellikleri aşınma nedenli problemlerde öne çlkmaktadır.

Bu çalışmada mevcut yüksek hızda oksi yakıt sprey (HVOF) esaslı termal sprey uygulamalara alternatif olarak 4140 çeliği üzerine fleksikord alev sprey tekniği ile Krom oksit esaslı kaplamaların daha ekonomik üretimi, proses optimizasyonu, kaplama mikroyapı karakterizasyonu (ısıl işlemsiz ve ısıl işlemli) ve aşınma performansları (ASTM G65) karşılaştırılmalı olarak incelenmiştir.

\section{Malzeme ve Yöntem (Material and Method)}

\subsection{Kaplama İşlemi (Coating Process)}

Termal sprey kaplama teknolojisinde kaplamanın altlı̆̆a yapışması ergiyik formundaki dropletlerin yüzeye hızla çarparak hızlı katılaşma esnasından mekanik kilitlenme sonucunda oluşmaktadır. Bu yapışmanın sağlıklı bir şekilde gerçekleşmesi iyi bir yüzey hazırlık işlem kalitesine bağlıdır. Bu yüzey kalitesini sağlamak için sırasıyla; 
yüzey temizleme (ultrasonik banyo), yüzey kumlama (6 bar, Alümina 80-100 mesh) ve kurutma işlemleri uygulanmıştır.

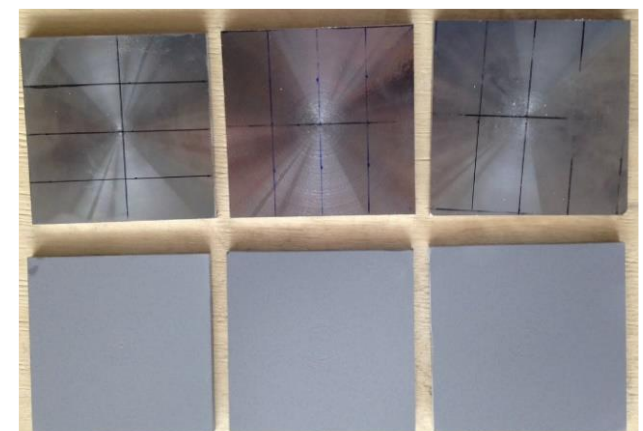

Şekil 2. Kumlama yapılmış 4140 çelik plakalar (Sandblasted 4140 steel plates)

$4 \mu$ m'luk homojen bir yüzey pürüzlülüğü elde edildikten sonra ön ısıtma $\left(150^{\circ} \mathrm{C}\right)$ işlemi yapılarak iç gerilmeleri azaltılmıştır. Kaplama işlemi iki kademede gerçekleştirilmiştir. İlk kademede seramik esaslı kaplamanın altlığa daha iyi yapışması ve termal genleşmeyi azaltması amacıyla bir bağ kaplama tabakası (NiCr esaslı, ortalama 40$100 \mu \mathrm{m})$ püskürtülmüştür. Sonrasında ise oksit esaslı Krom oksit tabakası yüzeye uygulanmıştır. Kaplamanın şematik gösterimi Şekil 3’te verilmiştir.

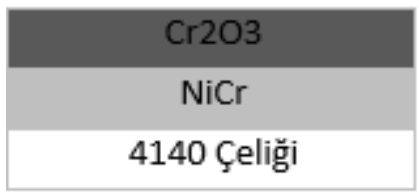

Şekil 3. Krom oksit kaplama şematik gösterimi (Schematic representation of chromium oxide coating)

$\mathrm{NiCr}$ ve $\mathrm{Cr}_{2} \mathrm{O}_{3}$ için proses parametreleri farklı olup, optimum parametrelerin tespiti için çalışmalar yapılmış olup aşağıda Tablo 1'de verildiği gibi belirlenmiştir. Oksijen (4 bar) ve Asetilen (1,2 bar) gaz basınçları her kaplamada aynıdır.

Üretilmiş olan kaplamalar, ekstrüder vidasının çalışma koşullarında maksimum $350^{\circ} \mathrm{C}$ ye ulaştığını göz önünde bulundurarak $400^{\circ} \mathrm{C}$ 'de 60 saat açık atmosfer ortamında ısıl işlem uygulanmıştır.

\subsection{Kaplamalara Uygulanan Testler ve Analizler (Tests and Analysis Applied to Coatings)}

Kaplamaların mikroyapısal incelemelerinde standart metalografik işlemler (500-1200-2400 grit SiC zımpara ve ardından $3 \mu$ alümina pasta ile parlatma) sonrasında taramalı elektron mikroskobu (SEM), Stereo mikroskop (SM), Optik Mikroskop (OM) çalışmaları ile yüzey ve kesit mikroyapıları incelenmiștir. Kaplamaların aşınma testleri ASTM G65 standartlarına uygun şekilde 130N yük altında dakikada 300-600 gr alumina aşındırıcı beslemesi ile 6000 devir dönme mesafesinde gerçekleştirilmiştir. Kaplamaların Mikrosertlik testleri ise Vickers sertlik ölçümü ile 300 gr yük uygulanarak 10 saniye süre ile gerçekleşmiştir. Kaplamanın her katmanından en az 3'er ölçüm yapılıp ortalamaları değerlendirmeye alınmıştır.

\section{Deneysel Sonuçlar (Experimental Results)}

\subsection{Kaplamaların Mikroskobik İncelemeleri (OM,SM) (Microscopic Examinations of Coatings)}

Termal sprey yöntemiyle üretilen kaplamalarda yüzeyde biriktirilen kaplama miktarı ancak kesitten alınan optik mikroskop görüntüsüyle ölçülebilmektedir. Kaplamanın aşınma dayanımı için önemli bir kriter olan kaplama kalınlıkları her katman için ayrı ayrı 3'er ölçüm olacak şekilde ölçülmüştür. Aşınma dayanımı için kaplama kalınlığı kadar önemli olan bir diğer husus da kaplama yüzeyinin pürüzlülügünün homojen bir yapıya sahip olması gerekmektedir. Yüzey morfolojileri için de üst yüzeyden stereo mikroskop ile görüntüler tablolara eklenmiştir.

Bu yöntemle üretilen kaplamaların görüntüleri aşağıda Şekil 4'te sergilenmektedir. Krom oksit tabakası görüleceği üzere ortalama $50 \mu \mathrm{m}$ kalınlığında biriktirilebilmiştir. Yüzeyi koyu gri renkte olup yüzey pürüzlülüğü Ra:3-5 $\mu \mathrm{m}$ seviyesindedir. 
Tablo 1. Kaplama parametreleri (Spraying parameters)

\begin{tabular}{lccc}
\hline \hline Tabaka & $\begin{array}{c}\text { Hava } \\
\text { Basınci } \\
\text { (bar) }\end{array}$ & $\begin{array}{c}\text { Mesafe } \\
\text { (mm) }\end{array}$ & $\begin{array}{c}\text { Besleme Hızı } \\
\text { (cm/dk) }\end{array}$ \\
\hline $\mathrm{NiCr}$ & 4,5 & $100-120$ & 100 \\
\hline $\mathrm{Cr}_{2} \mathrm{O}_{3}$ & $3,5-4,5$ & $100-80$ & 50 \\
\hline
\end{tabular}
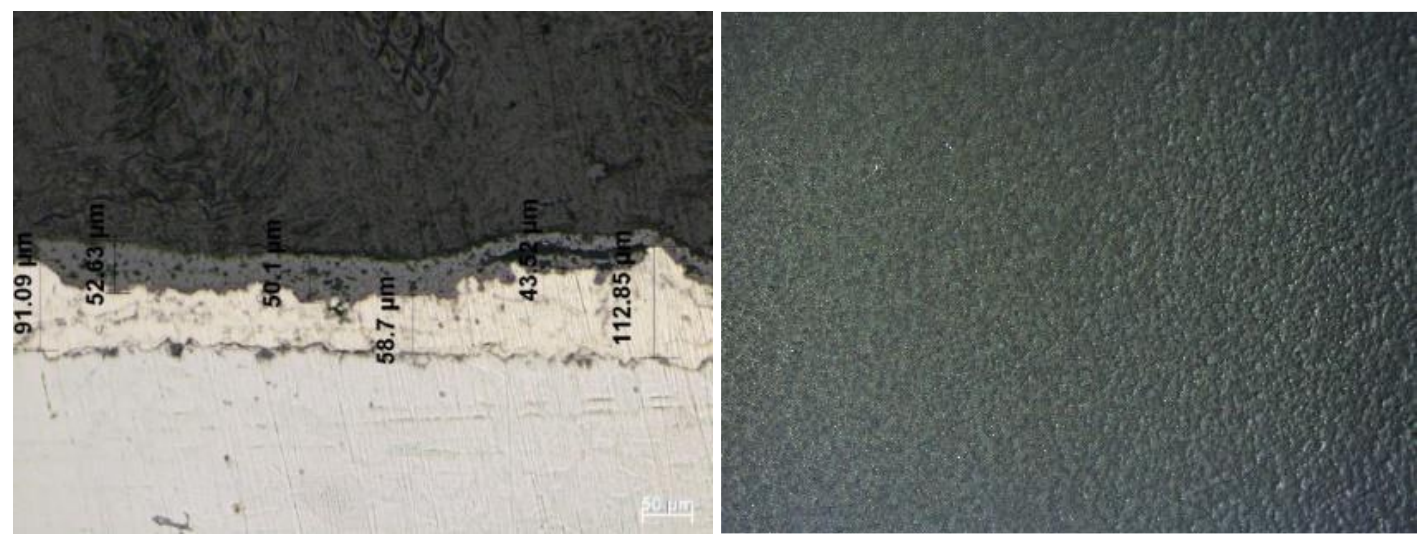

Şekil 4. Kesit ve üst yüzey görüntüsü (Cross section and top surface view)

Isıl işlem öncesi kaplamaların özellikleri Tablo 2'de özetlenmektedir. Görüleceği üzere son katta bulunacak olan Krom oksit tabakasının yüzey pürüzlülüğünden doğacak yüzey kalitesi çok yüksektir.

Tablo 2. Kaplamaların genel özellikleri (General properties of coatings)

\begin{tabular}{cccc}
\hline $\begin{array}{c}\text { Kompozisyon } \\
(\%)\end{array}$ & $\begin{array}{c}\text { Yoğunluk } \\
\left(\mathbf{g} / \mathbf{c m}^{3}\right)\end{array}$ & $\begin{array}{c}\text { Porozite } \\
(\%)\end{array}$ & $\begin{array}{c}\text { Pürüzlülük } \\
(\text { Ra } \boldsymbol{\mu m})\end{array}$ \\
\hline $\begin{array}{c}\% 80 \mathrm{Ni} \\
\% 20 \mathrm{Cr}\end{array}$ & 7,25 & $1-3$ & $6-8$ \\
\hline$\% 99,2 \mathrm{Cr}_{2} \mathrm{O}_{3}$ & 5,2 & 1 & $\sim 3$ \\
\hline
\end{tabular}

\subsection{Kaplamaların Mikrosertlik Ölçüm Sonuçları (Microhardness Measurement Results of Coatings)}

Bu çalışmada kaplamanın sertliği aşınma performansı açısından oldukça önemli bir kriterdir. Bu sebeple hem oksit tabakaları hem bağ tabaka hem de altlık malzemenin hem ısıl işlemli hem de ısıl ișlemsiz durumdaki sertlikleri

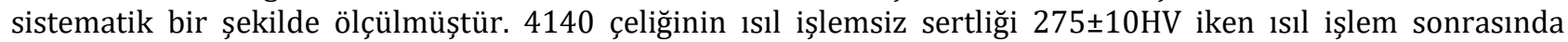
$265 \pm 10 \mathrm{HV}$ olduğu gözlemlenmektedir. Bağ tabakanın ise ısıl işlemsiz halde $210 \pm 20 \mathrm{HV}$ iken ısıl işlem sonrasında $230 \pm 20 \mathrm{HV}$ olarak sertlikte bir artış olduğu gözlemlenmiştir.

Krom oksit esaslı kaplamalarda Tablo 3'te görüldüğü üzere ısıl işlem sonrası sertlik değerlerinde artış gözlenmektedir. Bu durum kaplamanın sinterleşme etkisiyle sertlik artışına etki ettiğini göstermektedir.

Tablo 3. Krom oksit esaslı kaplamaların mikrosertlik değerleri $\left(\mathrm{HV}_{0,3}\right)$ (Microhardness values of chromium oxide based coatings)

\begin{tabular}{cccc}
\hline & $\mathbf{4 1 4 0}$ & $\mathbf{N i C r}$ & $\mathbf{C r}_{2} \mathbf{O}_{3}$ \\
\hline \hline T0 & $275 \pm 10$ & $210 \pm 20$ & $1112 \pm 16$ \\
\hline T460 & $265 \pm 10$ & $230 \pm 20$ & $1282 \pm 23$ \\
\hline
\end{tabular}




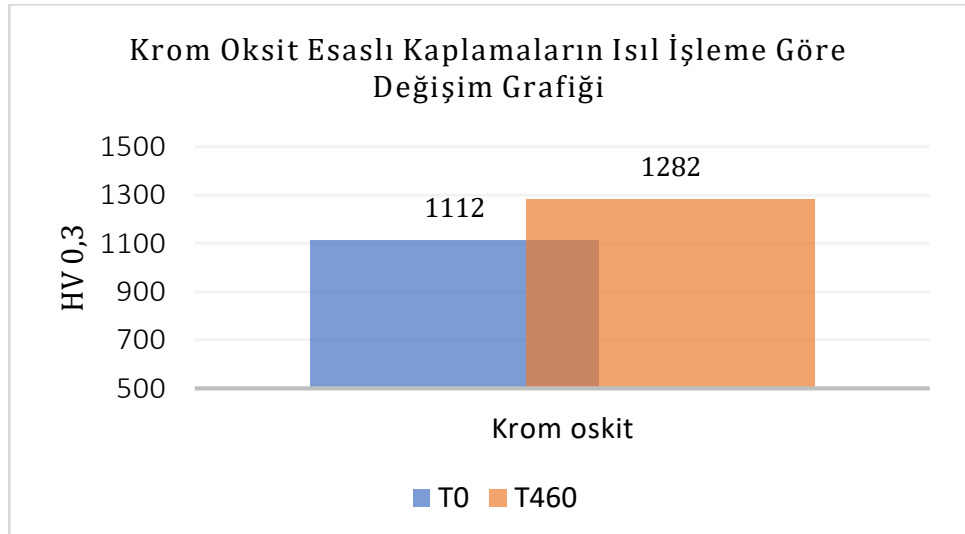

Şekil 5. Krom oksit kaplamalarında sertlik değişimi grafiği (Hardness change graph in chromium oxide coatings)

Yukarıda Şekil 5’te Krom oksit esaslı kaplamalarının ısıl işlem sonucunda sertlik değişimleri sütun grafikleriyle sergilenmektedir. Bu kaplama kompozisyonu için ısıl işlem şartları sertlik artışına neden olmaktadır.

\subsection{Kaplamaların Așınma Testi Sonuçları (Wear Test Results of Coatings)}

Kaplamaların aşınma testleri ASTM G65 standardı kapsamında gerçekleștirilmiştir. Bu test döner bir disk (kauçuk) yardımı ile katı sert partüküllerin yüzeyde abrasiv aşındırma etkisiyle gerçekleşir. Testler her numune için aynı koşullarda yapılmış olup test sonuçları kütlece ve hacimce hesaplanmıștır.

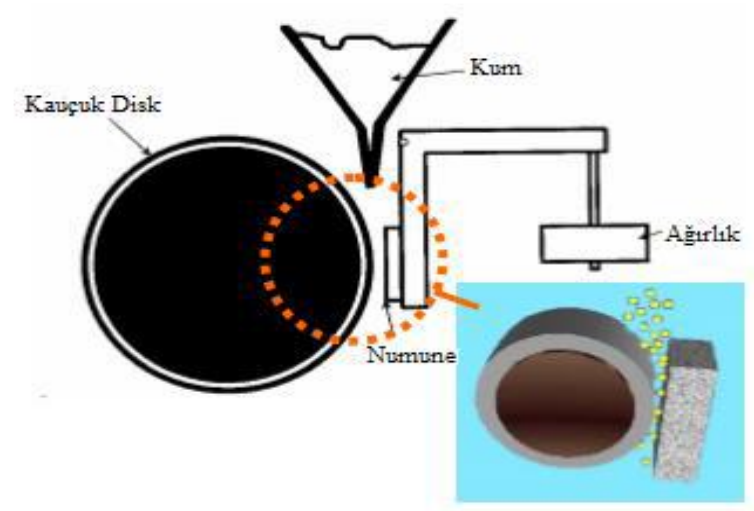

Şekil 6. ASTM G65 aşınma testi temsili şekli (ASTM G65 wear test system)

Așınma testleri sonuçları kaplamasız ve kaplamalı yüzeyler ve ısıl işlemli ve ısıl işlemsiz yüzeyler için karşılaştırmalı olacak şekilde gerçekleștirilmiştir. Așınma testi sonrası aşınma izleri yüzey profilometre sistemi ile ölçülmüş ve sonrasında elektron mikroskobunda aşınma mekanizmaları değerlendirilmiştir.

Tablo 4'te altlık malzeme olarak kullanılan 4140 çeliğinin oda sıcaklığında ve $400^{\circ} \mathrm{C}$ de 60 saat ısıl işlem sonrası aşınma kayıpları sergilenmektedir. Isıl işlem sonrasında aşınma kaybının beklenildiği üzere arttığı gözlenmiştir. Ekstrüder sisteminde $350-400^{\circ} \mathrm{C}$ gibi sıcaklıklara çıkılması durumunda alașımın kaplamasız olarak kullanılması durumunda aşınma kaybının artması olasıdır. Bu nedenle mutlak surette kaplama uygulaması zorunludur. Sertlik ölçümlerinde de ısıl işlem sonrası azalmanın aşınma kaybını artırdığı gözlenmektedir.

Tablo 4. 4140 altlı̆̆ının ağırlıkça ve hacimce malzeme kayıpları (Losses by weight and volume of the 4140 substrate)

\begin{tabular}{cccc}
$\begin{array}{c}\text { Alaşım } \\
\text { Türü }\end{array}$ & Isıl işlem & $\begin{array}{c}\text { Ağırlıça } \\
\text { Malzeme } \\
\text { Kaybı (gr) }\end{array}$ & $\begin{array}{c}\text { Hacimce Malzeme } \\
\text { Kaybı(mm }{ }^{3}\end{array}$ \\
\hline 4140 & T0 & 0,621 & 85,91 \\
\hline 4140 & T460 & 0,648 & 89,79 \\
\hline
\end{tabular}




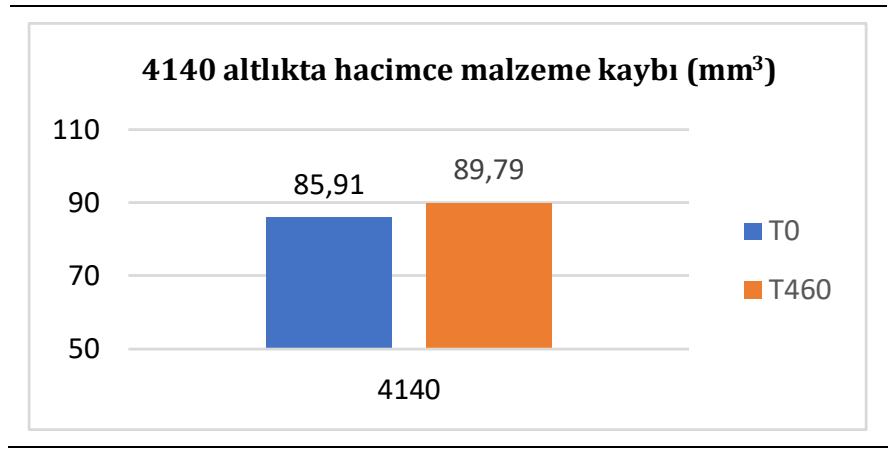

Şekil 7'de 4140 çeliğinin ASTM G65 testi sonrası ısıl işlemli ve ısıl işlemsiz hallerinin aşınma izleri görüntüleri sergilenmektedir. Görüleceği üzere ısll işlemli numunenin aşınma izinin daha geniş bir yüzey alanına sahip olduğu gözlenmiştir.
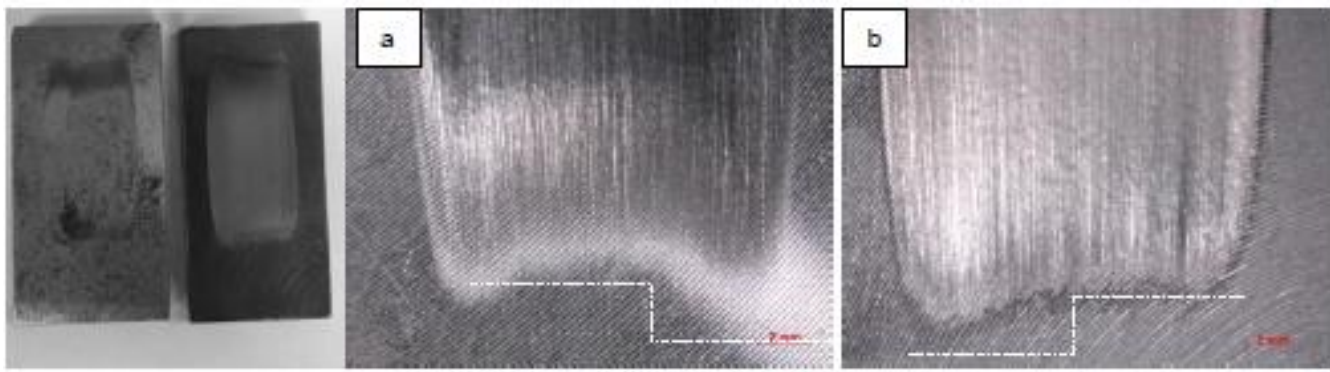

Şekil 7. Isıl işlemsiz (a) ve ısıl işlemli (b) 4140 altlığının aşınma izi uç bölgelerinin profili stereo mikroskop görüntüsü (Stereo microscope images of the wear track zones on the 4140 substrate without heat treatment (a) and heat treatment (b) conditions
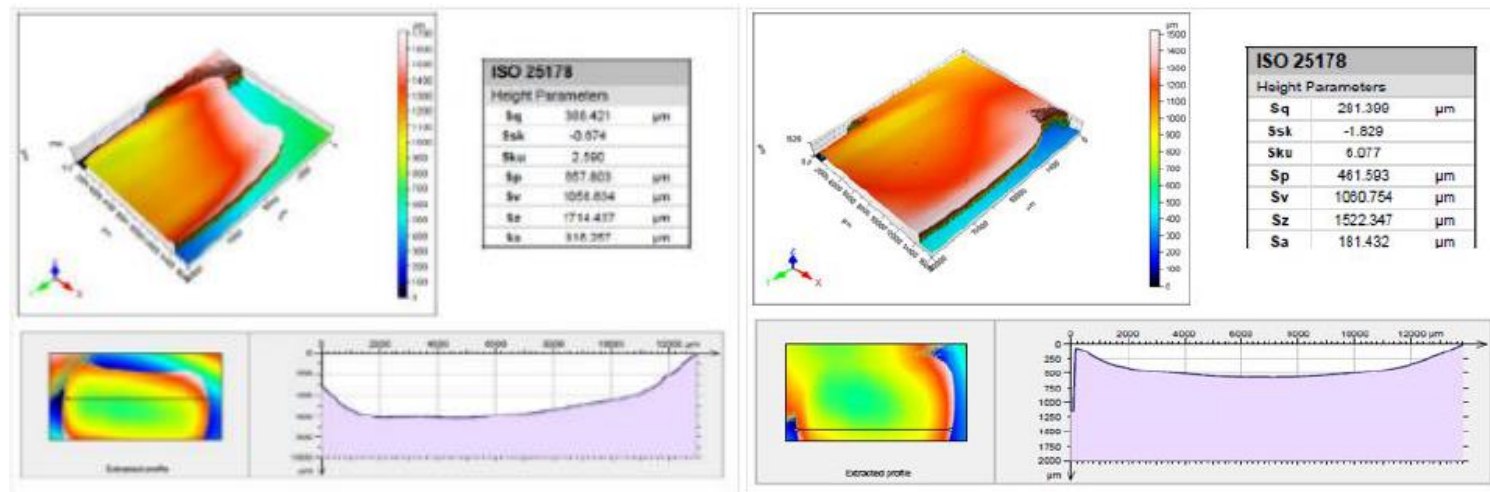

Şekil 8. Isıl işlemsiz ve ısıl işlemli 4140 çeliğinin test sonrası aşınma izi profilometresi

(Wear track profilometry of non-heat-treated and heat-treated 4140 steel surfaces)

Şekil 8'de üç boyutlu yüzey profilometresi ile taranan yüzeylerin aşınma izi profili gösterilmektedir. Isıl işlemli numunenin yüzey oksidasyonu sonucunda yüzeyin karardığı ve oluşan oksit tabakasının aşınma testi esnasında yüzeyden ayrılması sonunda daha geniş bir yüzeyde aşınma oluşturduğu gözlenmektedir. Așınma izi bölgesi aşınmamış bölgeye göre daha parlak bir renktedir. Aşınma izlerinin iç bölgesi incelendiğinde yüzeyler düzgün ve pürüzsüz bir form oluşturmaktadır. Aşındırıcı partiküller ile temas eden yüzeylerde ince ve uzunlamasına çizikler göz ile görülebilmektedir. Katı aşındırıcı partiküllerin yüzeyde oluşturduğu deformasyon ve mikro kesme sonucunda oluşan keskin köşeli tanelerin yol açtığı izler açıkça görülebilmektedir. Aşınma izi boyutları 15mm x $30 \mathrm{~mm}$ boyutları arasında değişmektedir. Aşınma derinliği ısıl işlemli numunede en yüksek $390 \pm 25 \mu \mathrm{m}$ arasında bir çukurcuk oluşturmaktadır. Isıl işlemsiz numunede ortalama $654 \pm 40 \mu \mathrm{m}$ derinliğinde bir aşınma izi gözlenmiştir. Bu farklılığın temel sebebi ısıl işlemli yüzeyde oluşan oksit tabakasının aşınmayı başlatması sonrasında altlık kesitinden içeri doğru aşınmanın ilerlemesidir. Isıl işlemsiz numunede ise aşındırıcı partiküller doğrudan yüzeyden içeri doğru kazıma ile aşındırmayı gerçekleştirmektedir. Bu nedenle aşınma izi derinliklerinde farklılık oluşmaktadır.

Termal sprey tekniği ile 4140 çeliği üzerinde biriktirilen Krom esaslı oksit kaplamaların aşınma kayıpları Tablo 5 'te sergilenmektedir. Tabloda hem ısıl işlem öncesi hem de ısıl işlem sonrası hacimce ve ağırlıkça aşınma kayıpları incelendiğinde ssıl işlemli numunelerde daha az hacimce aşınma kaybı gözlenmektedir. Kaplamasız altllk 
yüzeyinde aşınma değerleri ile karşılaştırıldığında her kaplama kompozisyonu daha düşük bir aşınma kaybı sergilemiştir.

Tablo 5. A Ăırlıkça ve hacimce malzeme kayıpları (Material losses by weight and volume)

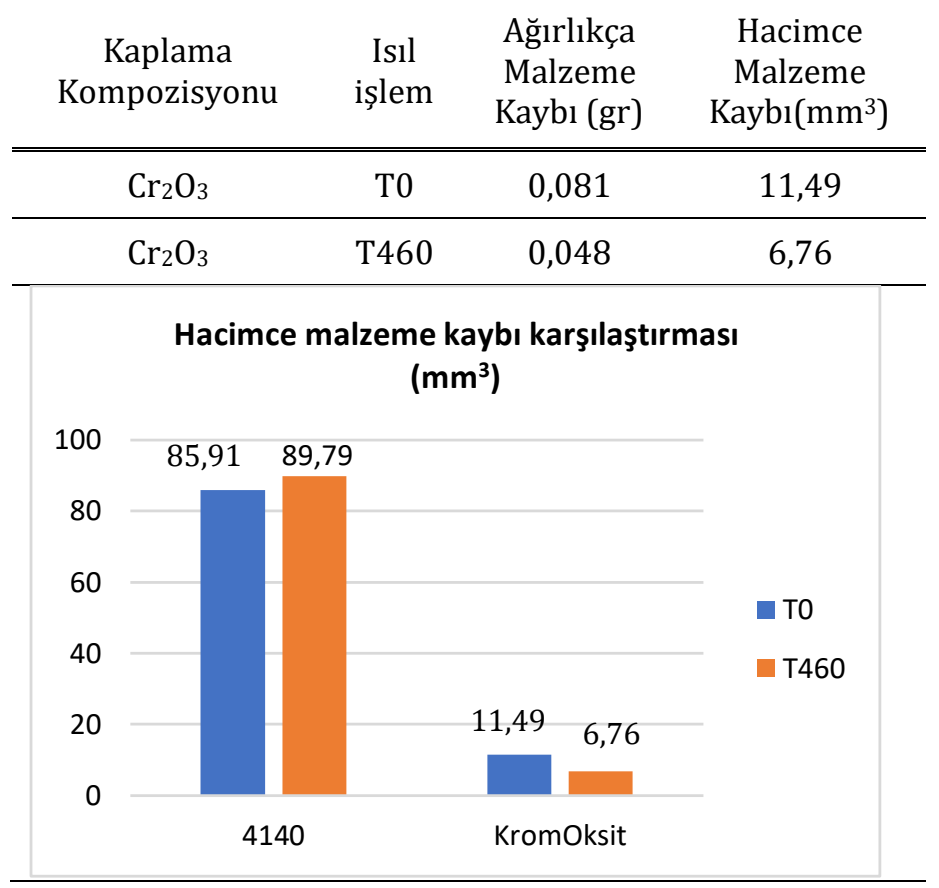

Şekil 9'da ısıl işlemsiz ve ısıl işlemli olarak 4140 çeliğinin ve krom oksit tabakasının aşınma izi görüntüleri karşılaştırılmaktadır. Isıl işlem sonrasında numunelerin üst yüzey renklerinde belirgin farklılıklar gözlenmektedir. Bununla birlikte aşınma iz boyutları da değişmiştir. Isıl işlemli numunelerde iz boyutları ısıl işlemsizlere göre daha küçük olduğu gözlenmektedir.
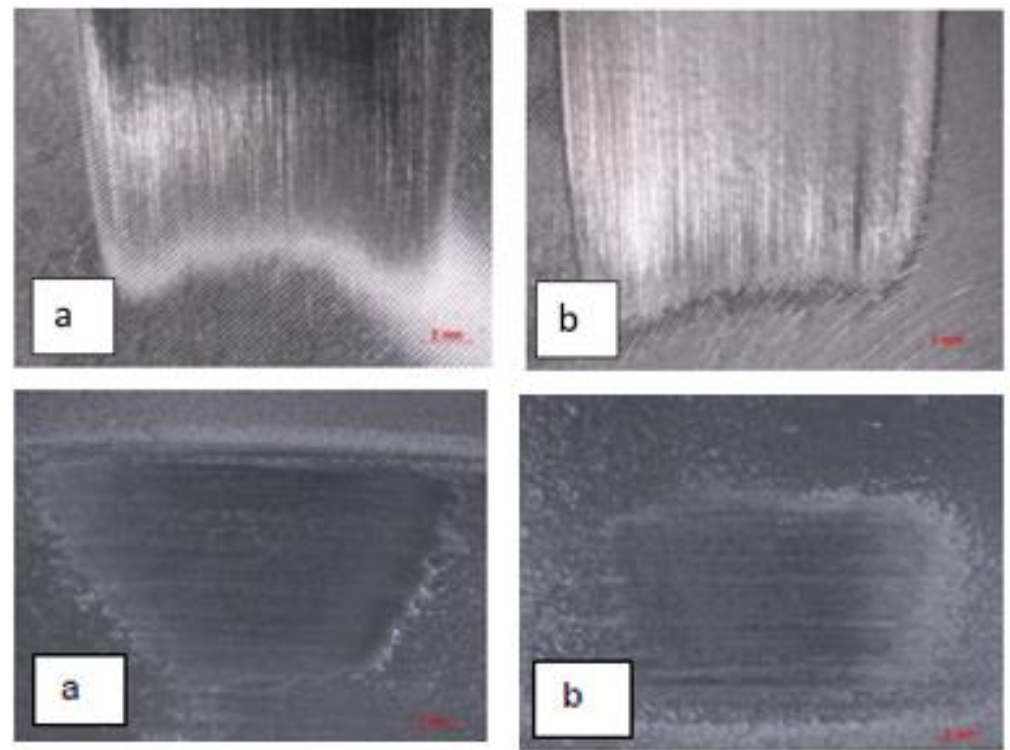

Şekil 9. Isıl işlemsiz (a) ve ısıl işlemli (b) 4140 krom oksit esaslı kaplamanın aşınmış bölge stereo görüntüsü (Stereo image of the worn region of the 4140 chromium oxide-based coating without heat treatment (a) and with heat treatment (b))

Krom oksit esaslı kaplamasında aşınma izi yüzey profili aşağıda Şekil 10'da sergilenmektedir. Isıl işlemsiz halde aşınma izi derinliği daha belirgin ve fazladır. Kaplama kalınlığı düşük olmasına karşın kaplamada aşınma kaybı en düşük seviyededir. 

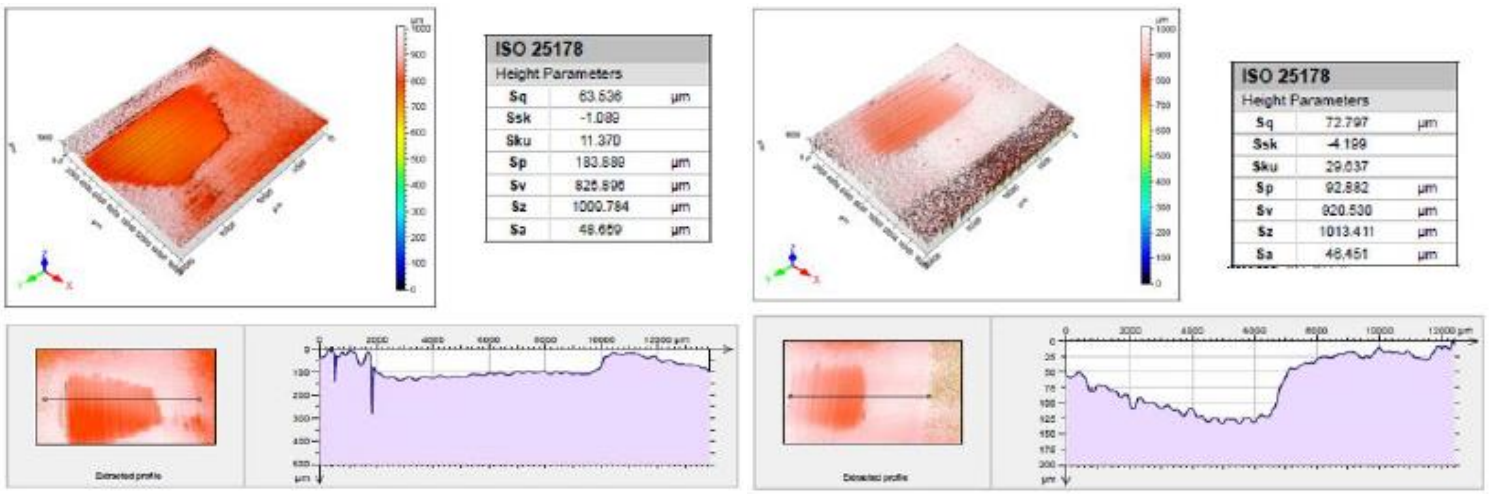

Şekil 10. Krom oksit esaslı kaplamanın aşınma testi sonrası 3 boyutlu aşınma izi profilometresi (3D wear trace profilometry after the wear test of the chromium oxide-based coating)

Yapılan bu çalışmada Tablo 5'te görüleceği üzere ısıl işlemsiz 4140 çeliği hacimce 85,91 mm² malzeme kaybettiği görülürken Krom oksit esaslı kaplama hacimce 11,49 $\mathrm{mm}^{3}$ malzeme kaybediyor. Krom oksit kaplamalarda, 4140 çeliğine nazaran çok daha düşük aşınma kaybı görülmektedir (Yüksek aşınma direnci). $400^{\circ} \mathrm{C}$ de 60 saat ısıl işlem sonrasında 4140 çeliği hacimce 89,79 mm³ malzeme kaybına uğrarken Krom oksit esaslı kaplamada hacimce 6,76 $\mathrm{mm}^{3}$ malzeme kaybı oluşuyor. Isıl işlem koşullarına (sinterleşme) bağlı olarak yapısal süreksizliklerin azalması ve olası faz dönüşümünün bu aşınma kaybı azalmasında etkin rol oynadığı düşünülmektedir. Ekstrüder vida yüzeylerinde krom oksit esaslı kaplamaların rahatlıkla kullanılabileceği öngörülmektedir.

\subsection{Aşınma İzleri Üzerinde Elektron Mikroskobu İncelemeleri (Electron Microscopy Studies on Wear Marks)}

Așağıda Șekil 11 de tek katmanlı ısıl ișlemli krom oksit tabakasının elektron mikroskobunda așınma izi bölgesi incelenmiştir. Așınma izi bölgesinde 3 farklı bölgeden görüntü alınmıștır. Așınmayan kaplama bölgesinden, aşınma izi merkez bölgesinden ve aşınma izi geçiş bölgesinden. Görüleceği üzere kaplama 1 no'lu bölgede kaplamanın hemen altındaki bağ tabakaya ulaşılmasına karşın en iyi abrazif aşınma direnci elde edilmiştir. Yüzeyde $100 \mu$ m kalınlığın altında bir kaplama tabakasının sağladığı direnç altlığın korunmasında önemli rol oynamıştır. 2 no'lu bölgede ise üst oksit tabakası ile bağ tabaka geçiş zonu oluşturmakta ve aşınma izi profilini oluşturmaktadır. Bu bölgede hem bağ tabaka hem de üst tabaka kalıntıları bir arada yer almaktadır.

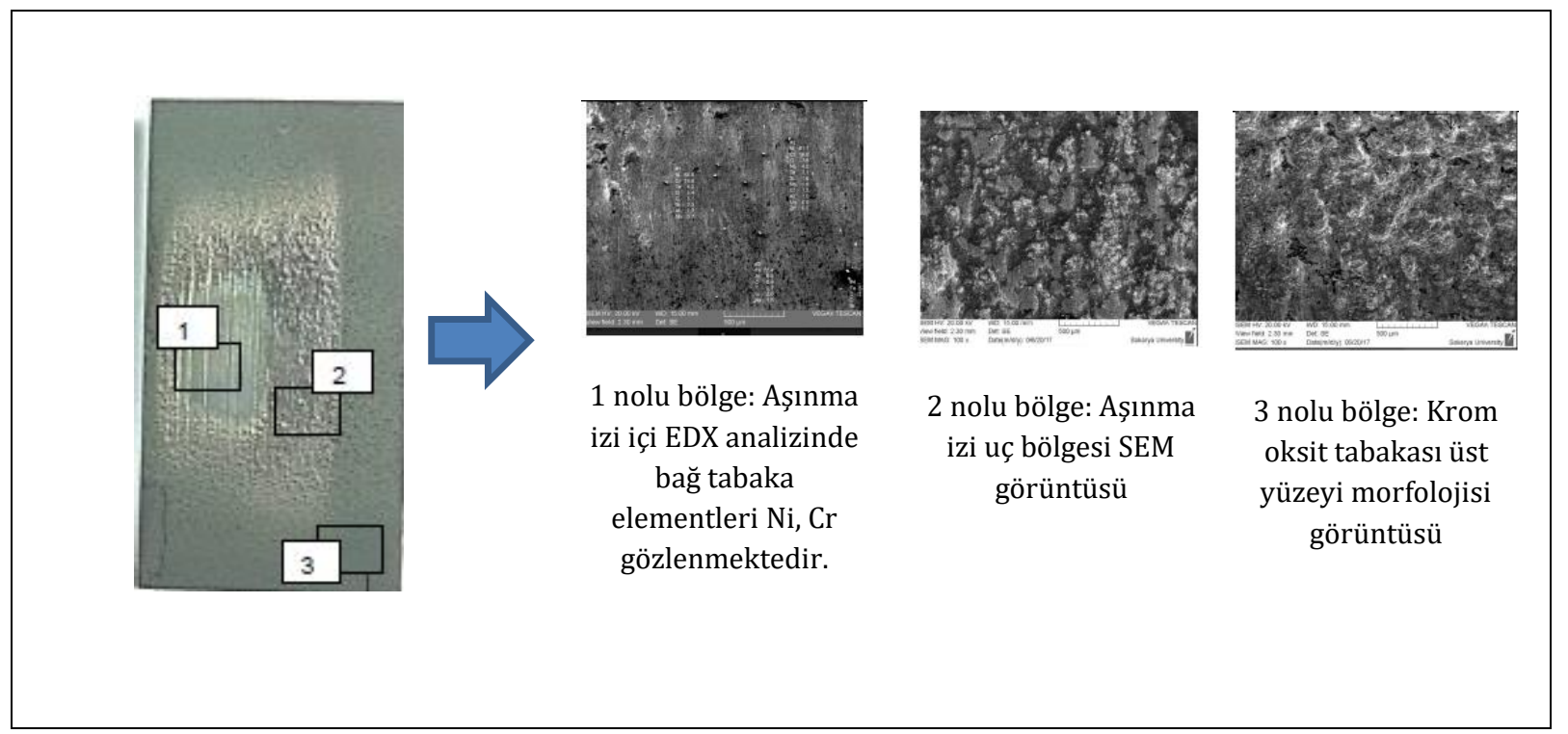

Şekil 11. Isıl işlemli krom oksit esaslı kaplamanın elektron mikroskobu aşınma izi incelemesi (Electron microscope wear trace examination of heat-treated chromium oxide-based coating)

\section{Sonuç ve Tartışma (Conclusion and Discussion)}

Deneysel çalışmalarda termal sprey teknikleri ile farklı kompozisyonlarda fleksikord kaplama malzemeleri kullanılarak bağ tabaka olarak kullanılan NiCr ve krom oksit 4140 çeliği üzerinde biriktirilebilmiştir. Önceden belirlenen deneme çalışmalarında elde edilen optimum sprey parametreleri ile kaplamaların üretimi 
gerçekleștirilmiştir. Kaplamaların türüne ve sprey parametrelerine bağlı olarak kaplama yapısal özelliklerinin değiştiği açık bir şekilde gözlenmektedir. Özellikler kullanılan sarf malzemelerin (fleksikord) toz tane boyutunun kaplama yüzey kalitesi ve ara yüzey özellikleri üzerindeki etkisi kaplamanın aşınma performansı üzerinde etkin olduğu tespit edilmiştir. Kaplama işlemleri sırasıyla yüzey hazırlama, kaplama parametrelerinin optimizasyonu ve kaplamaların üretimi doğrultusunda tamamlanmıștır. Kaplama sonrasında ısıl işlem uygulanarak hedef uygulama alanı olan ekstrüder vidalarda çalışma şartları belirlenerek (maksimum $400{ }^{\circ} \mathrm{C}$ ) kaplamanın aşınma performansı oda sıcaklığında test sonuçları ile karşılaştırmalı olarak ölçülmüştür. Deneysel amaçlı plakalar üzerinde yapılan işlemlerden sonra kaplamalar metalürjik açıdan karakterize edilmiş, aşınma kayıpları ağırlıkça ve hacimce ölçülmüştür. Elektron mikroskobunda hem kesit hem üst yüzey hem de aşınma izleri irdelenmiş, yüzey profilleri üç boyutlu tarayıcıda analiz edilmiştir. Așınma mekanizması ve aşınmaya etki eden faktörler detaylı bir şekilde tartışılmıştır.

- 4140 nitrasyon çeliği üzeride yapılan aşınma testlerinde hacimce aşınma kaybı ısıl işlem öncesinde $85 \mathrm{~mm}^{3}$ olup ısıl işlem sonrasında aşınma hızı daha da artmaktadır. Alaşımın $400^{\circ} \mathrm{C}$ de sıcaklıklara maruz kalması kaplamasız halde alaşımın ömrünü önemli ölçüde azaltmaktadır. Bu nedenle mutlak surette vidaların koruyucu aşınmaya dirençli kaplamalara gereksinimi ortaya çıkmaktadır.

- Çalışma hedefleri arasında ekstrüder vida alaşımı üzerinde hacimce maksimum $50 \mathrm{~mm}^{3}$ aşınma kaybı olması arzulanmıştır. Bu doğrultuda üretilen kaplamaların hem ısıl işlemsiz halde hemde ısıl işlem sonrasında aşınma kaybı hedefini sağladığı belirlenmiştir. Termal sprey kaplama yöntemlerinin başarılı bir şekilde uygulanabileceği ortaya çıkarılmıştır.

- En yüksek aşınma direnci (hacimce aşınma kaybı <15 $\mathrm{mm}^{3}$ ) kromoksit esaslı kaplamalarda elde edilmiştir. Isıl işlem sonrasında aşınma kaybı önemli ölçüde azaltılarak $10 \mathrm{~mm}^{3}$ 'ün altına indirilebilmiştir.

- Isıl işlem öncesinde kaplama yapısında splatlar arası boşlukların ısıl işlemden sonra azalmasıyla birlikte (sinterleşme etkisi) daha yoğun bir kaplama tabakası ve sertlik artışı elde edilebilmiştir. Bu durum kaplamaların aşınma performansının iyileşmesine neden olmuştur.

- Kaplamaların aşınma iz profilleri incelendiğinde aşınma mekanizmasında mikro kesme, yüzeyden parça ayrılması ve mikron ölçeğinde sıvanma etkisi ile aşınmanın gerçekleştiği tespit edilmiştir.

\section{Teşekkür (Acknowledgement)}

Bu çalışma TUBİTAK 2209-B Sanayiye Yönelik Lisans Araştırma Programı Destekleme Programı tarafından 1139B411601028 nolu proje kapsamında desteklenmiştir. Bu projede Sanayici tarafında bize destek sağlayan Düzce'de faaliyetlerini sürdüren STANDARD PROFİL firmasına teşekkürü borç biliriz. Yine bu çalışmada kapılarını bize açan SUBÜ-SUMAR ailesine sonsuz teșekkürlerimizi sunarız.

\section{Çıkar Çatışması (Conflict of Interest)}

Yazarlar tarafından herhangi bir çıkar çatışması beyan edilmemiştir. No conflict of interest was declared by the authors.

\section{Kaynaklar (References)}

A. Kulkarni, A. Vaidya, A. Goland, S. Sampath, H. Herman, Processing effects on porosity-property correlations in plasmasprayed yttriastabilized zirconia coatings, Mater. Sci. Eng. A 359 (2003) 100- 111.

Ferrari, D.; Extrusion Coating Resins - Troubleshooting, TAPPI PLC Conference, 2000.

G. Bolelli,V. Cannillo, L. Lusvarghi, S. Ricc'o, Mechanical and tribological properties of electrolytic hard chrome and HVOFsprayed coatings, Surf. Coat. Technol. 200 (2006) 2995-3009.

Guagliano M., "Fatigue failure of a bar of a twin-screw extruder for plastics", Engineering Failure Analysis 12 (2005) 950-962

Song, E.P., Ahn, J., Lee, S., Kim, N.J., Effects of critical plasma spray parameter and spray distance on wear resistance of Al203-8 wt.\%TiO2 coatings plasma-sprayed with nanopowders, Surface and Coatings Technology 202, 2008, 3625-3632.

Handbook of Thermal Spray Technology, ASM International, Materials Park, OH, USA, p. 171.

Heimann, R.B., Plasma-spray coating, VCH, New York, 1996.

J.D. Gates, Two-body and three-body abrasion: a critical discussion,Wear 214 (1998) 139-146.

K. Sugiyama, S. Nakahama, S. Hattori, K. Nakano, Slurry wear and cavitation erosion of thermal-sprayed cermets, Wear 258 (2005) 768-775.

Q.Yang,T. Senda, A. Ohmori, Effect of carbide grain size on microstructure and sliding wear behaviour of HVOF-sprayed WC$12 \%$ Co coatings,Wear 254 (2003) 23-34.

R.B. Heimann, Applications of plasma-sprayed ceramic coatings, Key Eng. Mater. 122-124 (1996) 399-442.

R.Westergard, L.C. Erickson, N. Ax'en, H.M.Hawthorne, S. Hogmark, The erosion and abrasion characteristics of alumina coatings plasma-sprayed under different spraying conditions, Tribol. Int. 31 (1998) 271-279.

S. Guessasma, M. Bounazef, P. Nardin, T. Sahraoui, Wear behavior of alumina-titania coatings,analysis of process and parameters, Ceram. Int. 32 (2006) 13-19.

Sulzer-Metco web site, http://www.sulzermetco.com. 
Sun, Y., Li, B., Yang, D., Wang, T., Sasaki, Y., Ishii, K., Unlubricated friction and wear behaviour of zirconia ceramics, Wear 215, 1998, 232-236.

Wagner, J. R. Jr; Handbook of Troubleshooting Plastic Processes: A Practical Guide, John Wiley and Sons, 2012

Y. Xie, H.M. Hawthorne, Wear mechanism of plasma-sprayed alümina coating in sliding contacts with harder asperities, Wear 225-229 (1999) 90-103. 